\title{
LUDICIDADE, INFÂNCIA E EDUCAÇÃO: UMA ABORDAGEM HISTÓRICA E CULTURAL
}

\author{
Reginaldo Santos Pereira \\ Universidade Estadual do Sudoeste da Bahia (UESB) \\ reginaldouesb@gmail.com
}

\section{RESUMO}

O lúdico ocupa um lugar significativo em nossa cultura e no desenvolvimento humano, abrangendo tanto a atividade individual e livre quanto coletiva e regrada, em um movimento progressivo e integrado, que contribui para o desenvolvimento motor, cognitivo, afetivo, das relações sociais, culturais, éticas e estéticas. Este artigo intenciona apresentar uma abordagem histórica e cultural do papel da ludicidade na educação e na infância. Discute a necessidade de se pensar a constituição de uma cultura lúdica e educação estética nos processos educativos, bem como a reflexão acerca da transformação de nossos rígidos espaços-tempos de vida cotidiana, na tentativa de se (re) construir um diálogo multicultural em meio às diversas culturas silenciadas. Conclui-se a necessidade de resgatar e valorizar a cultura e o lúdico na vida, na escola e nos processos formativos. Para a viabilização de uma cultura lúdica e estética, requer um esforço e labor coletivos, movidos por uma epistemologia social, crítica, reflexiva e sensível aos choques e resistências, pois trata-se de tocar em estruturas sociais, culturais e disciplinares historicamente constituídas.

Palavras-chave: Ludicidade; Cultura; Educação; Infância.

\section{LUDIC, CHILDHOOD AND EDUCATION: AN APPROACH HISTORICAL AND CULTURAL}

\begin{abstract}
The ludic occupies a significant place in our culture and human development, covering both the individual and free as collective and regulated activity, on a progressive and integrated movement, which contributes to motor development, cognitive, emotional, relationships social, cultural, ethical and aesthetic. This article intends to present a historical and cultural approach to the role of ludic in education and childhood. It discusses the need to think about the creation of a ludic culture and aesthetic education in the educational processes as well as the reflection on the transformation of our hard timesspaces of everyday life, in an attempt to (re) build a multicultural dialogue among silenced the various cultures. The conclusion is the need to rescue and value the culture and the ludic in life, in school and in the formative processes. To the viability of a ludic and aesthetic culture, it requires an effort and collective labor, driven by a social epistemology, critical, reflective and sensitive to shock and resistance, because it is touching social structures, cultural and disciplinary historically constituted.
\end{abstract}

Keywords: Ludic; Culture; Education; Childhood. 


\title{
Introdução
}

\author{
Mas quando um poeta moderno diz que para \\ cada um existe uma imagem cuja contemplação \\ o mundo inteiro submerge, para quantas pessoas \\ essa imagem não se levanta de uma velha \\ caixa de brinquedos? \\ Walter Benjamin
}

Muitas imagens e momentos marcam nossas vidas. Lembranças familiares, a primeira professora, amigos de infância, músicas, jogos, brinquedos, brincadeiras, bonecas, praças e quintais. Brincamos de amarelinha, esconde-esconde, pega-pega, bicicleta, peão, iô-iô, carrinho, empinar pipas, bolinhas de gude, corridas, bonecas, médico, faz-de-conta, desenhar, contar histórias, dançar, cantar... brincamos com o colega da escola e também com os vizinhos. A atividade lúdica, o prazer dos jogos e das brincadeiras, atravessa gerações e culturas, faz parte do universo infantil e está ligada à vida adulta.

Apesar de as atividades lúdicas terem mudado muito desde o começo do século XX nos diferentes países e contextos sociais, o prazer dos jogos e do brincar parecem não ter se transformado. O prazer que envolve essas atividades se contrapõe aos momentos de tensão: é prazeroso, divertido e sério ao mesmo tempo. Embora existam diversas distinções entre o lúdico e suas manifestações, tais como jogos e brincadeiras, consideramos neste estudo o lúdico como atividade humana, "elemento da cultura" (HUIZINGA, 2000), que possibilita a construção de processos identitários e formativos dos sujeitos.

Vale destacar que os termos lúdico e jogo possuem significações polissêmicas, pois implicam um amplo leque de possibilidades e suas leituras são múltiplas. Huizinga (2000), ao realizar estudo sobre $A$ noção de jogo e sua expressão na linguagem afirma a heterogeneidade e instabilidade das designações da função lúdica:

O latim cobre todo o terreno do jogo com uma única palavra: ludus, de ludere, de onde deriva diretamente lusus [...]. Ludus abrange os jogos infantis, a recreação, as competições, as representações litúrgicas e teatrais e os jogos de azar [...]. É interessante notar que ludus, como termo equivalente a jogo em geral, não apenas deixa de aparecer nas línguas românicas mas igualmente, tanto quanto sei, quase não deixou nela qualquer vestígio. Em todas essas línguas, desde muito cedo, ludus foi suplantado por um derivado de jocus, de jogo em geral (HUIZINGA, 2000, p. 41-42).

A palavra lúdico carrega a conotação de prazer, ausência de tensão e de conflito; também liga-se à criatividade, à arte, à poesia, à construção e desconstrução da realidade; é um espaço-tempo pautado na imaginação, inventividade, fantasia, desejo e associa-se principalmente a ideia de jogo. Conforme aponta Brougère (1998), o termo jogo é utilizado e compreendido na própria ausência de definição rigorosa; jogo é o que o vocabulário científico denomina "atividade lúdica". Esse autor afirma que "a noção de jogo como o conjunto de linguagem funciona em um contexto social; a utilização do termo jogo deve, pois, ser considerada como um fato social: tal designação remete à imagem do jogo encontrada no seio da sociedade em que ele é utilizado" (p. 16).

Ortiz (2005, p. 15-16), ao discutir o conceito de jogo, explica que:

A palavra jugar (do latim iocari) significa fazer algo com espírito de alegria e com a intenção de se divertir ou de se entreter. A palavra jogo 
provém etmologicamente do vocábulo latino iocus, que significa brincadeira, graça, diversão, frivolidade, rapidez, passatempo. Para o estudo etimológico, deve-se considerar também o significado do vocábulo ludus-i: o ato de jogar, o prazer da dificuldade gratuita. Esse vocábulo latino dá mais um sentido ao jogo: ludus-ludere, ludus-us $e$ ludicrus [jogo, diversão, entretenimento] [...]. É quase impossível compreender os traços de uma pesquisa para o significado etimológico, já que aparece a transposição de significados na história da transnominação.

Nesse sentido, ao referirmo-nos ao jogo, buscamos abarcar as diversas manifestações do lúdico. Para Huizinga (2000, p. 3-4), o jogo "ultrapassa os limites da atividade física ou biológica. É uma função significante, isto é, encerra um determinado sentido. No jogo existe alguma coisa em jogo que transcende as necessidades imediatas da vida e confere um sentido à ação". Percebemos, portanto, que em Huizinga (2000) os termos lúdico e jogo são sinônimos e nesse estudo também adotamos tal procedimento.

Ao refletir a temática do lúdico Bujes (2000, p. 205-206) afirma que:

O tema do jogo, do brinquedo, do brincar tem atravessado épocas e culturas. Os brinquedos estão presentes na iconografia do século $\mathrm{XV}$, magistralmente representados nas cenas flamengas de Brüeghel, nos contos recolhidos pelos irmãos Grimm da tradição oral alemã, nas reflexões de Walter Benjamin, na poesia de Vinicius de Moraes, nas canções de Chico Buarque, nas manifestações da arte popular e, sobretudo, na fantasia das crianças.

$\mathrm{Na}$ afirmação anterior, a autora enfatiza que manifestações lúdicas perpassaram o século XV até os dias atuais e se encontram presentes em diversas formas artísticas e culturais. O jogo constitui-se, assim, um conceito com propriedades amplas que assumem significados distintos dependendo da época e do lugar, e foi estudado por historiadores (Huizinga, Caillois, Ariès), filósofos (Aristóteles, Benjamin, Dewey, Platão, Pascal, Schiller, Wittgenstein), antropólogos (Brougère), psicólogos (Bruner, Elkonin, Freud, Piaget, Vigotski, Wallon, Winnicott), educadores/teóricos do passado (Froebel, Chateau) e contemporâneos (Friedmann, Kishimoto, Luckesi, Moyles, Murcia, Ortiz), dentre outros.

Muitos estudos (BENJAMIN, 2002; BROUGÈRE, 1998; 2002; FRIEDMANN, 1996; ORTIZ, 2005; ROCHA, 2005; WAJSKOP, 1997; KISHIMOTO, 1998; 2000; 2003) têm demonstrado o quanto o lúdico ocupa um lugar importante na cultura e no desenvolvimento humano, abrangendo tanto a atividade individual e livre quanto a atividade coletiva e regrada, num movimento progressivo e integrado que contribui para o desenvolvimento das relações sociais e culturais. Esses autores afirmam também a relevante contribuição das atividades lúdicas para o desenvolvimento da criança e a formação humana nos seus múltiplos aspectos: cognitivo, afetivo, social, motor, ético e estético, visto que expressam a forma pela qual uma criança reflete, organiza, constrói e reconstrói o mundo à sua maneira.

O jogo sempre esteve unido à vida e cultura dos povos, à sua história, ao mágico, ao sagrado, ao amor, à literatura, às artes, à poesia, à música, à dança, aos costumes, e até mesmo à guerra. Ele sempre propiciou o vínculo entre os povos e a comunicação entre os seres humanos, sendo, portanto, uma prática cultural (ORTIZ, 2005).

Observando a presença do lúdico na evolução do ser humano, Huizinga (2000) classifica o jogo como fenômeno antropológico que potencializa a identidade do grupo social contribuindo para fomentar a coesão e a solidariedade e, portanto, favorece os sentimentos de comunidade; afirma que as sociedades são marcadas pelo jogo desde o seu 
início. Esse autor aponta duas características básicas do jogo e acrescenta o discernimento que a criança constrói entre o real e o imaginário como uma terceira possibilidade do jogo. Essas duas características são:

$\mathrm{O}$ ato de ser livre, de ser ele próprio liberdade. Uma segunda característica, intimamente ligada à primeira é que o jogo não é vida "corrente" nem vida "real". Pelo contrário, trata-se de uma evasão da "vida real" para uma esfera temporária de atividade com orientação própria. Toda criança sabe perfeitamente quando está "só fazendo de conta" ou quando está "só brincando" (HUIZINGA, 2000, p. 11, grifos do autor).

As análises feitas por Caillois (1986), na obra Los juegos y los hombres, apresentanos a seguinte caracterização do jogo:

Não há dúvida de que o jogo se deve definir como uma atividade livre e voluntária, como fonte de alegria e de diversão. Um jogo em que se está obrigado a participar deixaria de ser um jogo: se constituiria em coerção. Obrigatório ou simplesmente recomendado, perderia uma de suas características fundamentais: o fato de que o jogador se entrega a ele espontaneamente, de bom grado e por seu gosto, tendo cada vez mais a total liberdade de preferir se retirar, o silêncio, o recolhimento, a solidão ou uma atividade fecunda (CAILLOIS, 1986, p. 31).

Entendemos que pensar a cultura lúdica é ir além do seu sentido comum - folclore, vestimentas, costumes alimentares, entre outros - podemos inseri-la nas práticas de todos os dias e nos coletivos humanos, pois apresenta componentes como imaginação, espontaneidade, criatividade, fantasia, expressividade, cultivo da sensibilidade, busca da afetividade, nutrientes essenciais aos processos formativos.

Ortiz (2005, p. 22) afirma que:

O jogo é criança, adolescente, homem, velho, percorre as etapas evolutivas, nasce, viaja, acompanha o ser humano e morre com ele [...]. Comprovamos que, por meio do jogo, o ser humano se introduz na cultura e, como veículo de comunicação, amplia sua capacidade de comunicação e de representação simbólica da realidade. Realmente, poderíamos dizer que, com o jogo, é intensificada a vida cultural do homem, ela se enriquece [...]. O jogo faz cultura, a cultura faz vida: o jogo é vida e a vida, cultura.

A seguir, apresentamos como o lúdico em seu percurso histórico se apresenta como uma prática cultural dos seres humanos, e que se faz presente em qualquer idade, não podendo ser visto apenas como lazer, diversão e atividade infantil, pois remete a outros itinerários, transforma e deixa-nos plenos, atuando nas dimensões cognitiva, afetiva, social, motora, ética e estética.

\section{O lúdico na história: uma prática cultural}

O lúdico faz parte da cultura e está presente nas atividades humanas. Isso por si só já significa contrapor-nos ao mundo estrito do trabalho que desumaniza, mecaniza o homem e as suas relações. O trabalho também deveria ser lúdico. Por outro lado, em 
termos das crianças, não se pode identificar o lúdico apenas com o brinquedo, ou melhor, como brincadeira livre, sem objetivo, sem parceria entre crianças e adultos. Nessa perspectiva, compreendemos que o lúdico não é coisa só de criança, é de todos nós, uma dimensão cultural fundamental e não apenas brincadeira. Está nas brincadeiras, nos jogos, mas também em outras atividades infantis.

Mas houve um tempo em que a infância esteve ligada à dependência dos adultos e a criança partilhava dos trabalhos e festas destes. Segundo Ariès (1981), foi apenas nos séculos XV e XVI que, nas sociedades ocidentais, as crianças foram afastadas das atividades adultas. A infância como um período particular somente se consolidou no século XVII. Ariès, em seu estudo História social da criança e da família, ao apresentar sua Pequena contribuição à história dos jogos e das brincadeiras, mostra-nos como, a partir do século $\mathrm{XV}$, na iconografia, por exemplo, os artistas multiplicaram a representação de crianças brincando. Reconhece-se nessas pinturas o cavalo de pau, o catavento, o pássaro preso por um cordão e, às vezes, embora mais raramente, o uso de bonecas.

Ariès (1981) narra e registra de forma minuciosa a infância de Luís XIII, o Delfim de França, e afirma que no início do século XVII os jogos e as brincadeiras eram comuns a crianças e adultos. Esse autor relata-nos também que:

Ao mesmo tempo em que brincava com bonecas, esse menino de quatro e cinco anos praticava o arco, jogava cartas, xadrez (aos seis anos) e participava de jogos dos adultos, como o jogo de raquetes e inúmeros jogos de salão. Aos três anos, o menino já participava de um jogo de rimas, que era comum às crianças e aos jovens [...]. Quando ele não está brincando com os pajens, está brincando com os soldados de diversas brincadeiras, como de bater palmas e de esconder. Aos seis anos, joga o jogo dos ofícios e brinca de mímica, jogos de salão que consistiam em adivinhar as profissões e as histórias que eram representadas por mímica. Essas brincadeiras também eram brincadeiras de adolescentes e de adultos (ARIÈS, 1981, p. 86).

Ariès (1981) ainda relata que em Paris no século XVII inventaram os brinquedos chamados fantoches. Eles divertiram e dominaram Paris inteira, de tal forma que não se poderia ir a casa alguma sem encontrar alguns pendurados nas lareiras.

Por volta de 1600 a especialização das brincadeiras atingia apenas a primeira infância; depois dos três ou quatro anos, ela se atenuava e desaparecia. A partir dessa idade, a criança jogava os mesmos jogos e participava das mesmas brincadeiras dos adultos, quer entre crianças, quer misturada aos adultos. Sabemos disso graças principalmente ao testemunho de uma abundante iconografia, pois, da Idade Média até o século XVIII, tornou-se comum representar cenas de jogos (ARIÈS, 1981, p. 92).

Outro aspecto importante na cultura lúdica desse período está relacionado aos divertimentos nos jogos das grandes festas sazonais e tradicionais que se realizavam em datas fixas do calendário, onde se firmavam um dos principais meios (músicas, danças, representações dramáticas, jogos de bola) de que dispunha a sociedade para estreitar seus laços coletivos e se sentir unida. Ora as crianças, ora elas e os jovens participavam dos jogos delas em pé de igualdade com todos os outros membros da sociedade, e quase sempre desempenhavam um papel que lhes era reservado pela tradição (ARIĖS, 1981).

Ariès (1981) traduz como exemplo dessas festas a de Santos Reis e Natal, com participação ativa das crianças nas cerimônias. O dia dos "Santos-Inocentes", a "terça-feira 
gorda", que começava com brigas de galo que durava toda a manhã, e à tarde todos os jovens da cidade saíam para os arredores, para jogar o famoso jogo de bola que reunia várias comunidades numa ação coletiva, opondo ora duas paróquias, ora dois grupos de idades.

Um outro grupo de festas da infância e da juventude se situava no início de novembro (4 e 8 de novembro). Tratava-se de uma mascarada de jovens e não apenas de crianças. Segundo Ariès (1981), "essa festa desapareceu de nossos costumes, banida pela proximidade do dia de Finados, no entanto, ela sobreviveu na América anglo-saxônia com o nome de Halloween" (p. 100). Outra manifestação lúdica que acompanhava, sem distinção de faixa etária, as atividades de crianças, jovens e adultos nesse período era a música e a dança. Assim como a música e a dança, as representações dramáticas reuniam toda a coletividade e misturavam as idades tanto dos atores como dos espectadores.

Para Ariès (1981), os estudos históricos acerca dos jogos e brincadeiras nos conduzem a uma conclusão importante:

Partimos de um estado social em que os mesmo jogos e brincadeiras eram comuns a todas as idades e a todas as classes. O fenômeno que se deve sublinhar é o abandono desses jogos pelos adultos das classes sociais superiores, e, simultaneamente, sua sobrevivência entre o povo e as crianças das classes dominantes (ARIÈS, 1981, p. 124).

Desde o século XVII até o século XIX, apesar da incorporação paulatina de novos objetos, ocorreram poucas mudanças nas formas de manifestação do lúdico. A partir do século XIX a situação começa a se transformar em função de uma progressiva especialização e distinção entre classes sociais, faixas etárias e gênero. Benjamin (1994), no artigo intitulado História cultural do brinquedo, nos traz a seguinte reflexão:

Somente no século XIX a produção de brinquedos será objeto de uma indústria específica. $\mathrm{O}$ estilo e a beleza dos antigos tipos só podem ser compreendidos se levarmos em conta a circunstância de que outrora os brinquedos eram subprodutos das atividades produtivas regulamentadas corporativamente, o que significava que cada oficina só podia produzir o que correspondesse ao seu ramo. Quando durante o século XVIII começou a surgir uma fabricação especializada, ela teve que enfrentar em toda parte restrições corporativas. Elas proibiam que os carpinteiros pintassem suas bonecas de madeira, e a produção de brinquedos de vários materiais obrigava diversas indústrias a dividirem entre si o trabalho mais simples, o que encareceria a mercadoria (BENJAMIN, 1994, p. 245).

A partir da ampliação do processo de industrialização do século XX, a utilização de novos materiais, a introdução de dispositivos mecânicos e eletrônicos entre os objetos, especialmente os brinquedos, bem como o papel da mídia e das grandes corporações empresariais e industriais impactaram a nossa cultura lúdica. Para Benjamin (1994), "o brinquedo começa a emancipar-se: quanto mais avança a industrialização, mais ele se esquiva ao controle da família, tornando-se cada vez mais estranho não só às crianças, como também aos pais" (p. 246).

As reflexões de Brougère (2000), na obra Brinquedo e cultura, nos apontam que,

Quer a lamentemos, quer nos resignemos ou a aceitemos com entusiasmo, a mídia desempenha nas sociedades ocidentais um papel considerável, tanto entre aos adultos quanto entre as crianças [...]. É fato 
que nossa cultura e, talvez, mais ainda a das crianças, absorveu a mídia e, de um modo privilegiado, a televisão. A televisão transformou a vida e a cultura cotidiana da criança, as referências de que ela dispõe. Ela influenciou, particularmente, sua cultura lúdica (BROUGÈRE, 2000, p. $50)$.

Nessa perspectiva, observa-se que as transformações econômicas e sociais ocorridas no século XX, com a industrialização e mecanização das atividades produtivas, influenciaram a vida local e cotidiana, a organização escolar, familiar, trabalho e, sobretudo, as relações culturais, inclusive as vivências lúdicas, sendo a mídia televisiva um dos principais veículos para a consolidação desse processo de mudança e o distanciamento entre brinquedos, crianças e famílias.

Ao analisar a influência da publicidade nas manifestações lúdicas, Brougère (2000) destaca que:
A evolução da publicidade televisiva, consequentemente, influenciou fortemente o brinquedo: ele está cada vez mais ligado a uma história, é personalizado, na maior parte das vezes através de um desenho animado, e está ligado a um determinado universo [...]. Seja diretamente por intermédio das emissões dos programas ou indiretamente através dos brinquedos que se adaptaram à sua lógica, a televisão intervém muito profundamente na brincadeira da criança, na sua cultura lúdica [...]. Isso não significa que a cultura lúdica da criança esteja inteiramente submissa à influência da televisão (BROUGÈRE, 2000, p. 58).

No século XX, podemos verificar que o lúdico reconhecido como expressão cultural e educativa converteu-se, por exemplo, em um direito inalienável das crianças, e foi reconhecido na Declaração Universal dos Direitos das Crianças aprovada pela Assembléia das Nações Unidas de 20 de novembro de 1959, e ratificada pelo Brasil, no art. 84, inciso XXI, da Constituição Federal de 1988: “a criança terá ampla oportunidade para brincar e divertir-se, visando os propósitos mesmos da sua educação; a sociedade e as autoridades públicas empenhar-se-ão em promover o gozo deste direito (Art. $7^{\circ}$ )"; e na Convenção das Nações Unidas sobre os Direitos das Crianças, aprovada pela ONU em 20 de novembro de 1989 e oficializada como carta magna internacional, da qual o Brasil também foi signatário: "os Estados reconhecem à criança o direito ao repouso e aos tempos livres, o direito de participar em jogos e atividades recreativas próprias da sua idade, de participar livremente na vida cultural e artística (Art. 31)" (ONU/UNICEF, 1989).

Há consenso que toda criança tem o direito de ser criança, o que inclui o direito à educação e ao brincar, mas cabe questionar: em que medida o lúdico tem sido incorporado nas práticas escolares e como tal incorporação vem acontecendo? Buscamos fundamentar as nossas reflexões a esse respeito, a partir de análises propostas por Huizinga (2000): "Em que medida a cultura atual continua se manifestando através de formas lúdicas? Até que ponto a vida dos homens que participam dessa cultura é dominada pelo espírito lúdico?" (p. 217). Para esse autor, nas sociedades contemporâneas o lúdico vem perdendo espaço. Segundo ele, o próprio lúdico vem sendo invadido por uma tendência regulamentadora e sistematizadora, o que nos parece poder ser exemplificado nos dias atuais pelo esporte e atletismo ou até mesmo na política (HUIZINGA, 2000). E, por fim, questionamos: quais são os desafios, os limites, as possibilidades e os itinerários a seguir para construirmos uma educação lúdica, estética e prazerosa?

A partir destes questionamentos, cabe ampliar a reflexão acerca do papel do lúdico nos contextos educativos contemporâneos. Nesse sentido, convém deixar claro que, o 
lúdico a que nos referimos no presente estudo relaciona-se com a cultura e constitui-se como atividade cultural que se ramifica por todas as esferas da vida humana. Consideramos importante especificar um conceito de cultura que associamos à noção de lúdico, pois "encontramos o jogo na cultura, como um elemento dado existente antes da própria cultura, acompanhando-a e marcando-a desde as mais distantes origens até a fase da civilização em que nos encontramos" (HUIZINGA, 2000, p. 6).

Concordamos com o conceito de cultura apresentado pelo antropólogo Clifford Geertz na obra Interpretação das culturas, na qual caracteriza-a como rede de sistemas simbólicos e um conceito semiótico.

Como sistemas entrelaçados de signos interpretáveis, a cultura não é um poder, algo ao qual podem ser atribuídos casualmente os acontecimentos sociais, os comportamentos, as instituições ou os processos; ela é um contexto, algo dentro do qual eles podem ser descritos de forma inteligível - isto é, descritos com densidade (GEERTZ, 1978, p. 24).

Esse autor refuta a posição decorrente do iluminismo e da antropologia clássica sobre um homem ideal e afirma que um conceito semiótico de cultura tem seu impacto no conceito de homem, "sem os homens certamente não haveria cultura, mas, de forma semelhante, sem cultura não haveria homens. Somando tudo isso, nós somos animais incompletos e inacabados que nos completamos e acabamos através da cultura" (GEERTZ, 1978, p. 61). Para ele,

O homem não pode ser definido nem apenas por suas habilidades inatas, como fazia o iluminismo, nem apenas por seu comportamento real, como o faz grande parte da ciência social contemporânea, mas sim pelo elo entre eles, pela forma em que o primeiro é transformado no segundo, suas potencialidades genéricas focalizadas em suas atuações específicas. É na carreira do homem, em seu curso característico, que podemos discernir, embora difusamente, sua natureza, e apesar de a cultura ser apenas um elemento na determinação desse curso, ela não é o menos importante. Assim como a cultura nos modelou como espécie única - e sem dúvida ainda está modelando - assim também ela nos modela como indivíduos separados (GEERTZ, 1978, p. 64).

A partir da concepção de cultura apresentada, compreendemos que o lúdico faz parte da cultura produzida pelos sujeitos nas suas relações sociais cotidianas.

De certo modo, a civilização sempre será um jogo governado por certas regras, e a verdadeira civilização sempre exigirá o espírito esportivo, a capacidade de fair play. O fair play é simplesmente a boa fé expressa em termos lúdicos. Para ser uma vigorosa força criadora de cultura, é necessário que este elemento lúdico seja puro, que ele não consista na confusão ou no esquecimento das normas prescritas pela razão, pela humanidade ou pela fé (HUIZINGA, 2000, p. 232).

Brougère (2002) enfatiza que a cultura lúdica compreende tanto o conjunto de estrutura de jogos, que não se limitam às de jogos com regras, tradicionais ou recentes, quanto o conjunto de jogos de imitação ou de ficção. $O$ autor também destaca que a cultura lúdica se apodera de elementos da cultura do meio-ambiente da criança - questões de sexo, idade, classe social - e dos conteúdos da cultura mais ampla como personagens de 
histórias, filmes, desenhos animados e toda sorte de objetos, brinquedos, jogos, jogos eletrônicos, videogames etc.

Nos dias atuais, é visível o impacto das transformações culturais na literatura, artes, sistemas filosóficos, de crenças, morais, religiosos, as tecnologias de informação e comunicação, dentre outros, enfim, em todos os âmbitos da vida social e cotidiana das instituições, na família, no trabalho e na escola. Entretanto, vale ressaltar que este processo social de transformações não é homogêneo, pois existem particularidades sociais, culturais e familiares; mas acreditamos que, em geral, as transformações a que nos referimos têm haver com uma prevalência do ter ou possuir algo em detrimento do ser ou adquirir algum atributo pessoal e interior.

Benjamin (1994), no ano de 1936, em seu escrito $O$ narrador, analisa as transformações que se operam na dimensão das narrativas, e denuncia tais mudanças no jeito de contar histórias, que com o avanço das formações capitalistas passam a ser cada vez mais breves. Para ele,

\begin{abstract}
A arte de narrar está definhando porque a sabedoria - o lado épico da verdade - está em extinção. Porém esse processo vem de longe. Nada seria mais tolo que ver nele um "sintoma de decadência" ou uma característica "moderna". Na realidade, esse processo, que expulsa gradualmente a narrativa da esfera do discurso vivo e ao mesmo tempo dá uma nova beleza ao que está desaparecendo, tem se desenvolvido concomitantemente com toda uma evolução secular das forças produtivas (BENJAMIN, 1994, p. 200-20).
\end{abstract}

É importante observar que este processo de abreviação também se revela em outras práticas lúdicas, por exemplo, através das novas configurações do brincar (os games, jogos eletrônicos virtuais) influenciadas pela mídia e marcadas pelo imperativo do consumo. Benjamin (2002) faz importante reflexão sobre a transformação do brinquedo na segunda metade do século XIX, como efeito do processo de industrialização, que vai marcar o distanciamento entre as crianças e seus pais, os quais antes produziam juntos o brinquedo.

Nada é mais adequado à criança do que irmanar em suas construções os materiais mais heterogêneos - pedras, plastilina, madeira, papel. Por outro lado, ninguém é mais casto em relação aos materiais do que crianças: um simples pedacinho de madeira, uma pinha ou uma pedrinha reúnem na solidez, no monolitismo de sua matéria, uma exuberância das mais diferentes figuras [...]. Madeira, ossos, tecidos, argila, representam nesse microcosmo os materiais mais importantes, e todos eles já eram utilizados em tempos patriarcais, quando o brinquedo era ainda a peça do processo de produção que ligava pais e filhos. Mais tarde vieram os metais, vidro, papel e até mesmo o alabastro (BENJAMIN, 2002, p. 92).

Ao analisar a transformação radical dos brinquedos no século XX, tanto no modo de constituí-lo como de consumi-lo, Brougère (2004) analisa que:

A matéria plástica se afirmou definitivamente como o material do brinquedo, deixando para a madeira apenas um lugar secundário para aqueles que queriam se diferenciar, surgiram os jogos eletrônicos que passaram a ter um mercado importante, os programas de televisão para crianças, os canais se multiplicaram e a propaganda televisiva de brinquedos descobriu o que mostrar, os desenhos animados passaram a 
ser vitrines para os brinquedos, a grande distribuição, especializada ou generalizada, se impôs, a concentração e a globalização foram confirmadas, sendo o mercado dominado por algumas multinacionais americanas e japonesas e, enfim, surgiu a Internet (BROUGÈRE, 2004, p. 13).

Uma concepção de cultura lúdica e, por conseguinte, de uma educação estética, aparece como um conjunto vivo, diversificado conforme indivíduos e grupos, em função de hábitos lúdicos. Isso significa que a experiência cultural lúdica e estética não é apenas transferida para o indivíduo, mas o sujeito torna-se um co-construtor ou reconstrutor dessa dimensão (BROUGÈRE, 2002).

Schiller (1990) enfatiza que "o homem joga somente quando é homem no pleno sentido da palavra, e somente é homem pleno quando joga" (p. 83-84). No texto de apresentação da obra A educação estética do homem, de Friedrich Schiller (1990), o tradutor Márcio Suzuki afirma que "é mediante a cultura ou educação estética, quando se encontra no 'estado de jogo' contemplando o belo, que o homem poderá desenvolver-se plenamente, tanto em suas capacidades intelectuais quanto sensíveis [...] e no impulso lúdico, razão e sensibilidade atuam juntas e não se pode mais falar da tirania de uma sobre a outra" (idem, p. 16).

Diante do exposto, ao compreendermos o lúdico como inerente às relações sociais e práticas culturais da vida, podemos compreendê-lo como impulsionador de processos educativos. A cultura lúdica:

Origina-se das interações sociais, do contacto direto ou indireto (manipulação do brinquedo: quem o concebeu não está presente, mas trata-se realmente de uma interação social). A cultura lúdica como toda cultura é o produto da interação social [...]. A criança co-produz sua cultura lúdica, diversificada conforme os indivíduos, o sexo, a idade, o meio social (BROUGÈRE,2002, p. 27-28).

Resgatar e/ou valorizar a cultura lúdica na escola e nos processos formativos, significa redescobrir ou imaginar novos horizontes em busca de um projeto que contemple múltiplas dimensões do fazer humano. Afinal,

Devemos reaprender a brincar! [...] com o nosso corpo, o nosso espaço e os nossos objetos, com a imaginação, a criatividade, a inteligência; com a nossa intuição, com as palavras e com o nosso conhecimento, com nós mesmos e com os outros. Assim, estaremos redescobrindo essa linguagem para comunicar-nos e expressar-nos - a linguagem do lúdico (FRIEDMANN, 1996, p. 120).

\title{
A ludicidade na educação infantil: breve itinerário histórico
}

\author{
Há um menino \\ Há um moleque \\ Morando sempre no meu coração \\ Toda vez que o adulto balança \\ Ele vem me dar a mão. \\ Milton Nascimento
}

Para compreensão do papel do lúdico no contexto educativo, especificamente no espaço da educação infantil, apresentamos a seguir um breve percurso histórico do lúdico 
na educação dos pequenos, entrecruzando alguns olhares e caminhos desde a antiguidade até a contemporaneidade.

Kishimoto (2003) apresenta o surgimento dos jogos desde a Roma e Grécia antigas: Platão (428/427-347 a.C.), em As Leis, destaca a importância do "aprender brincando", em oposição à utilização da violência e da repressão. Da mesma forma, Aristóteles (384-327 a.C.) analisa a recreação como descanso do espírito na Ética a Nicômaco e na Política. O interesse pelo jogo aparece nos escritos de Horácio (65-8 a.C.) e Quintiliano (35-95) e referem-se às pequenas guloseimas em forma de letras, produzidas pelas doceiras de Roma, destinadas ao aprendizado da leitura. Entre os romanos, jogos destinados ao preparo físico voltaram-se para a formação de soldados, cidadãos obedientes, devotos e a influência grega acrescenta-lhes cultura física, formação estética e espiritual.

Vê-se que, nessa época, ainda não se discutia o emprego do jogo como atividade pedagógica e o interesse por tais atividades decresceu com o advento do Cristianismo, o qual impôs um modelo educacional disciplinador. No período medieval, a igreja condenou os jogos sob todas as suas formas, sem exceção nem reservas, particularmente nas comunidades de clérigos que deram origem aos colégios e universidades do antigo regime.

Os estatutos dessas comunidades nos dão uma idéia dessa intransigência. Ao lê-los, o historiador inglês das universidades medievais, J. Rashdall, ficou impressionado com a proscrição geral de todas as atividades de lazer, como a recusa em admitir que pudessem existir divertimentos inocentes, em escolas cujos alunos, entretanto, tinham basicamente entre 10 e 15 anos (ARIÈS, 1981, p. 109).

Neste período, prevalecem uma concepção e valorização das atividades intelectuais em detrimento das recreativas e lúdicas no processo de aprender e ensinar:

Na bula do cardeal de Amboise que fundava o colégio de Montaigu em 1501, havia um capítulo intitulado De exercitio corporali [...]. Na realidade o que o redator entende por exercícios físicos não são tanto os jogos, e sim todos os trabalhos manuais, por oposição aos trabalhos intelectuais. E ele dá primazia às tarefas domésticas, nas quais reconhece também uma função de relaxação: as tarefas de cozinha, de limpeza, o serviço da mesa. "Em todos os exercícios acima (ou seja, nas tarefas domésticas), nunca se deverá esquecer que se deve ser tão rápido e vigoroso quanto possível!"’. Os jogos só vêm depois das tarefas, e mesmo assim sob reservas! (ARIÈS, 1981, p. 110-111).

Essa atitude de reprovação dos jogos no contexto educativo modificou-se paulatinamente com o advento das ideias humanistas do Renascimento ao longo dos séculos XVII e XVIII. Kishimoto (2003) enfatiza que o grande acontecimento do século XVI que coloca em destaque o jogo educativo é o aparecimento da Companhia de Jesus. Podemos destacar que já no final do período feudal, a Companhia de Jesus, em 1534, no período histórico denominado Contra-Reforma, por influência dos padres jesuítas e orientações de Ignácio de Loyola (1491-1556), bispo fundador da Companhia de Jesus e da obra Ratio Studiorum (Ordenamento dos Estudos), a concepção de ensino-aprendizagem ganha novos contornos; Ignácio Loyola compreendia a importância dos jogos para a formação do ser humano e preconizava sua utilização como recurso auxiliar do ensino.

Os humanistas do Renascimento, em sua reação antiescolástica, já haviam percebido as possibilidades educativas dos jogos. Mas foram os 
colégios jesuítas que impuseram pouco a pouco às pessoas de bem e amantes da ordem uma opinião menos radical com relação aos jogos. Os padres compreenderam desde o início que não era possível nem desejável suprimi-los, ou mesmo fazê-los depender de permissões precárias e vergonhosas. Ao contrário, propuseram-se a assimilá-los e a introduzi-los oficialmente em seus programas e regulamentos, com a condição que pudessem escolhê-los, regulamentá-los e controlá-los (ARIÈS, 1981, p. 112).

Kishimoto (2003), ao referir-se aos ideais humanistas do Renascimento, comenta que o século XVII provoca a expansão contínua dos jogos e que:

Esse processo é acompanhado por estudos de filósofos acerca da importância da imagem e dos sentidos para a apreensão do conhecimento. Comenius mostra, em 1657, na obra Orgis Sensualium Pictus, a relevância de imagens para a educação infantil [...]. A eclosão do movimento científico no século XVIII diversifica os jogos que passam a incluir inovações [...]. Popularizam-se os jogos. Antes restritos à educação de príncipes e nobres, tornam-se posteriormente veículos de divulgação e crítica (KISHIMOTO, 2003, p. 16).

No final do século XVIII, vamos acompanhar o surgimento de uma nova concepção de criança como ser dotado de uma natureza distinta do adulto. $\mathrm{O}$ advento do humanismo renascentista europeu, em contraposição aos princípios e valores educativos do período medieval, propõe-se a uma renovação pedagógica que tem como uma de suas preocupações a expansão da escolarização e valorização da infância, assegurando a este período da vida um lugar importante no contexto social.

As ideias de Rousseau (1712-1778), através da obra Emílio ou Da Educação, publicada pela primeira vez em 1762, dentre outros escritos, vão constituir um marco da pedagogia moderna e influenciar as propostas de educação infantil no século XIX.

Nessa obra, ele se opõe ao intelectualismo da "Época das Luzes", clama por uma concepção "natural" de vida e põe a criança no centro do processo educativo e da vida; teoriza sobre uma educação que considere as necessidades das crianças e que respeite os seus ritmos de crescimento (BROUGÈRE, 1998).

O início do século XIX vai presenciar o fim da Revolução Francesa (1799) e o surgimento de novas ideias pedagógicas que influenciaram significativamente os rumos da educação infantil. Segundo Kishimoto (2003), embora não tenha sido o primeiro a analisar o valor educativo do jogo, é com Friedrich Wilhelm August Froebel (1782-1852) que o lúdico passa a ser considerado como um elemento fundamental parra a aprendizagem e o ensino de crianças. Assim, surge o "jogo educativo", que toma espaço na escola maternal francesa e vai influenciar o pensamento pedagógico de John Dewey (1859-1952), Maria Montessori (1870-1952) e outros educadores no século XX.

Arce (2002) considera que Froebel incorporou às suas ideias de educação um conceito de natureza advindo dos estudos do filósofo Schelling (1775-1854), em que o estético ocupa lugar central. Essa centralidade decorria do fato de considerar a arte como o melhor caminho para se conhecer o absoluto, pois Deus seria justamente o grande artista; a natureza e o ser humano seriam suas obras.

Froebel (2001) absorve a ideia de continuidade e evolução das coisas da natureza, entendendo que "cada homem deve apresentar-se a si mesmo e aos outros como um modelo livre porque, em cada um, existe e se encerra a humanidade inteira", acrescenta que, "partindo desse critério acerca do homem e da anunciação de seu nascimento, a 
verdadeira educação pode prosperar, florescer e dar saborosos frutos" (FROEBEL, 2001, p. 31).

Para Arce (2002), Froebel incorporou à sua pedagogia, uma concepção de natureza como obra perfeita do espírito de Deus, em unidade indissolúvel com este. O educador alemão também defende que existe uma constante unidade entre os contrários e, por fim, a valorização do estético, através de sua insistência na necessidade de se trabalhar com as crianças a harmonia das formas, o que procurou concretizar nos chamados "dons" 1 . Todos os jogos de Froebel que envolvem os "dons" sempre começavam com as pessoas formando círculos, dançando, movendo-se e cantando, pois acreditava-se que assim atingiriam uma perfeita unidade.

Em sua obra clássica, A educação do homem, publicada pela primeira vez em 1826, Froebel apresenta seus princípios educativos e enfatiza a importância do brincar no desenvolvimento da criança. Para ele,

O brincar, o jogo - o mais puro e espiritual produto dessa fase de crescimento humano - constitui o mais alto grau de desenvolvimento do menino durante esse período, porque é a manifestação do interno, [...] engendra alegria, liberdade, satisfação e paz, harmonia com o mundo. Do jogo, emanam as fontes de tudo que é bom. O menino que joga tranquiilamente, como atividade espontânea, resistindo à fadiga, chegará seguramente a ser um homem também ativo, resistente, capaz de sacrificar-se pelo seu próprio bem e pelos demais (FROEBEL, 2001, p. 47).

Froebel consolida seu projeto com a criação dos Kindergarten (Jardins de Infância) na Alemanha. O primeiro Jardim de Infância foi criado em 1840, na cidade de Blankemburg, e destinado a crianças menores de 6 anos. Froebel foi pioneiro em reconhecer o jogo e a brincadeira como maneira que a criança utiliza para expressar sua visão de mundo, e também como atividades que provocam desenvolvimento na primeira infância. A criação dos Jardins de Infância e a introdução da brincadeira como recurso educativo influenciaram a expansão da educação infantil em todos os países no século XX.

A teoria froebeliana proporcionou subsídios para a compreensão da brincadeira como ação livre da criança e o uso dos "dons"2 - objetos suporte da ação docente, conhecidos hoje como materiais pedagógicos - permitem o desenvolvimento de atividades e a produção de conhecimentos que promoviam e valorizavam os jogos educativos. A teoria froebeliana concebe o brincar como atividade livre e espontânea, responsável pelo desenvolvimento físico, moral, cognitivo, e os "dons" ou brinquedos são objetos que subsidiam as atividades das crianças.

A chegada das ideias froebelianas no Brasil aconteceu no final do século XIX, com uma certa expansão da educação infantil em nosso país. Segundo Kuhlmann Jr. (2001), “já em 1875, no Rio de Janeiro, havia sido fundado o primeiro jardim deinfância privado do país, no Colégio Menezes Vieira, seguido da Escola Americana em 1877 em São Paulo, ligada a missionários norte-americanos" (p. 15). Mas é somente em 1896 que se cria o primeiro jardim de infância público do país anexado à Escola Normal Caetano Campos, em São Paulo.

Posteriormente, no Brasil há uma apropriação pela educação das teorias infantis presentes no movimento progressivista como as de Jonhn Dewey (1859-1952), Maria Montessori (1870-1952), Ovide Decroly (1871-1932), William Kilpatrick (1871-1965), Celéstin Freinet (1896-1966) entre outros, e a expansão das teorias psicológicas de Sigmund Freud (1856-1939), Jean Piaget (1896-1980) e L. S. Vigotski (1896-1934). Todos 
esses autores marcaram definitivamente as propostas pedagógicas para a infância, tornando-as mais científicas e produzindo uma nova postura em relação ao lúdico no desenvolvimento infantil e da participação ativa do sujeito no processo de ensino e aprendizagem.

Vale registrar que a história do atendimento educacional tanto às nossas crianças quanto aos adolescentes nem sempre foi prioridade para o estado brasileiro. A infância no decorrer da história da educação brasileira não recebeu um acompanhamento que atendesse eficazmente às suas necessidades e carências.

Segundo Kramer (1992), no que se refere ao atendimento da infância brasileira, até 1874 existiu institucionalmente a Casa dos Expostos ou Roda $^{3}$ para as crianças abandonadas das primeiras idades e a Escola de Aprendizes Marinheiros (fundada pelo Estado em 1873) para os abandonados maiores de doze anos.

As mudanças ocorridas no Brasil, no campo político, social e econômico no início do século XX, especificamente a partir da década de $30 \mathrm{com}$ a implementação dos projetos de industrialização, refletiram de modo significativo nas concepções e no tratamento oferecido às crianças e adolescentes. De acordo com Faria (2002, p. 30),

Para tirar o Brasil do atraso e construir uma nação moderna, os intelectuais das décadas de 20 e 30 acreditavam na reforma da educação e do ensino, e só dispunham do poder das ideias [...]. Já em 1932, o Manifesto dos Pioneiros da Escola Nova apresentava uma proposta para a educação brasileira sem excluir a idade pré-escolar.

A década de 30 é acompanhada do surgimento de uma nova instituição idealizada por Mário de Andrade, os Parques Infantis (PI) que começam a se estruturar no município de São Paulo, vinculada ao recém-criado Departamento de Cultura, e tinha como lema "educar, assistir e recrear" e se expandiu para outras localidades do país como o interior do estado de São Paulo, o Distrito Federal, Amazonas, Bahia, Minas Gerais, Recife e Rio Grande do Sul.

Segundo Faria (2002, p. 48-49),

Ao lado do folclore, jogos e brincadeiras eram as atividades principais do PI, fazendo com que as crianças participassem do projeto de construção da cultura nacional. Mário de Andrade não só acreditava que a criança não só aprende e consome a cultura do seu tempo, como também produz cultura, seja a cultura infantil de sua classe, seja reconstruindo a cultura à qual tem acesso [...]. Mário de Andrade não só fez o público ser público, como qualificou o serviço público, atendendo a uma clientela pouco atendida: os filhos dos operários, contemplados, portanto, com o direito à infância, isto é, com o direito ao não-trabalho, com o direito de brincar e criar a cultura infantil.

Além das mudanças ligadas à educação das crianças no início do século XX, estes sujeitos se tornam também campo de intervenção social, tendo duas tendências de orientação: uma jurídica e outra assistencial. A primeira ocorre com a formulação do Código de Menores de 1927, que procurou ordenar as práticas de assistência aos menores. Entretanto, o que se observa são a vinculação e identificação da pobreza desassistida com a criminalidade e a delinqüência.

A segunda tendência que podemos denominar de assistencial pode ser visualizada a partir da criação do Serviço de Assistência a Menores (SAM) em 1941, iniciativa que deveria preocupar-se com a problemática infantil, entretanto, atuando vinculado ao 
Ministério da Justiça, demonstrou tão somente a preocupação do governo com o combate à criminalidade infanto-juvenil, levando a experiência ao fracasso.

Conforme analisa Kramer (1992, p. 46),

De maneira geral, pôde-se depreender dos documentos do SAM uma visão idealista de criança, da qual "surgirão os homens do amanhã", o que permite supor sua concepção única de infância. O SAM não conseguiu cumprir a sua finalidade de prestar, em todo território nacional, amparo social, sob todos os aspectos, aos menores desvalidos e infratores da lei penal. Ficou conhecido como "vergonha nacional". Por este motivo e por não dispor, segundo diversos documentos, de condições necessárias para garantir a readaptação dos menores, foi proposta oficialmente, em 1964, a extinção do SAM. Era criada a Fundação Nacional do Bem-Estar do Menor (FUNABEM) que herdava o seu patrimônio e suas atribuições.

Rodrigues (2001) relata que, com a extinção do SAM, surge a oportunidade de propor uma nova forma de enfrentar a problemática do "menor", fato que se concretizou em décadas posteriores, com o advento do regime militar, o qual passou a ser o preceptor da questão. O Estado, sob a tutela dos militares, cria em dezembro de 1964 a Fundação Nacional do Bem-Estar do Menor (FUNABEM) e nos estados as FEBEM, e a problemática do "menor" passa a ser vista, no bojo das práticas autoritárias do regime, como uma questão de segurança nacional. O governo disseminava a ideia de que estavam preocupados com os problemas sociais e tentavam demonstrar que o bem-estar da criança e do adolescente era um elemento fundamental para a fixação dos objetivos nacionais permanentes.

O Estado por meio da FUNABEM veiculava uma imagem à opinião pública segundo a qual estaria atento ao "homem de amanhã". Este tipo de propaganda, longe de ser uma manifestação isolada fazia parte de uma ampla estratégia de comunicação do regime militar destinada a garantir sua manutenção no poder, que buscava, entre seus objetivos, o reconhecimento da opinião pública quanto à eficiência do Estado na área social (RODRIGUES, 2001, p. 60).

Percebe-se, portanto, que o estado brasileiro, ao longo da história, tendeu a institucionalizar o atendimento às crianças, todavia, não potencializou tais iniciativas, levando-as a reverterem em negação de direitos, às vezes subtração de convívio familiar e da formação de cidadãos com condições de exercitar plenamente sua cidadania.

Segundo Kuhlmann Jr. (2000), do início do século XX até meados da década de 70, as instituições de educação infantil viveram um lento processo de expansão, parte estava ligada aos sistemas de educação, atendendo crianças de 4 a 6 anos, e parte vinculada aos órgãos de saúde e de assistência, caracterizados por um contato indireto com a área educacional. A luta pela pré-escola pública, democrática e popular se confundia com a luta pela transformação política e social mais ampla. A eleição de candidatos de oposição em governos de estados e municípios imprimiu um ritmo à expansão das instituições muito mais intenso do que a intenção inicial dos planos do regime militar, sendo que a ampliação do trabalho feminino nos setores médios levou também a classe média a procurar instituições educacionais para seus filhos.

Contudo, a mobilização de amplos setores e movimentos sociais nos anos 70 e 80 comprometidos com as causas da cidadania possibilitaram a abertura política e redemocratização do país, representadas na elaboração da Constituição Federal de 1988. 
Os setores ligados às causas da infância e adolescência, de modo destacado as ONGs, contaram com o apoio das amplas forças sociais, e garantiram a aprovação da Lei 8069/90 - Estatuto da Criança e do Adolescente $(\mathrm{ECA})^{4}$, que, além de extirpar o estigma de crianças e adolescentes com a eliminação do termo "menor", trouxe, ao mesmo tempo, garantias aos direitos inalienáveis de todas as crianças, "[...] assegurando-lhes, por lei, ou por outros meios, todas as oportunidades e facilidades, a fim de lhes facultar o desenvolvimento físico, mental, moral, espiritual e social em condições de liberdade e dignidade" (ECA, Art. $\left.3^{\circ}, 1990\right)$.

Destaca-se nesse processo uma mudança conceitual no atendimento da infância e da juventude. Abandona-se o paradigma da infância em situação irregular e se adota o princípio de proteção integral à infância. $\mathrm{O}$ estado deixa de ser aquele que é o "tutor do menor", e passa àquele que tem por prerrogativa promover a efetivação dos direitos, considerando que a criança deixa de ser objeto de direito para ser sujeito de direitos.

Em 1996, temos a aprovação da Lei 9394/96, que instituiu as Diretrizes e Bases da Educação Nacional, consolidando-se como um marco importante para ratificar o direito das crianças de 0 a 6 anos a educação. Apesar de apresentar apenas três artigos sucintos que tratam da educação infantil (artigos 29, 30 e 31), essa lei trouxe avanços significativos por reafirmar que a educação das crianças com menos de 6 anos de idade é a primeira etapa da educação básica.

No que diz respeito ao lúdico, os dispositivos legais e documentos oficiais do MEC (1998a, 1998b) destacam a necessidade da organização de espaços na educação infantil contendo parques infantis, brinquedotecas, brinquedos, entre outros, que oportunizem as diferentes manifestações de linguagens (plástica, visual, motora, artística, dramática etc.) da criança. De acordo com o Referencial Curricular Nacional para a Educação Infantil (1998b, p. 15):

Ao brincar, jogar, imitar e criar ritmos e movimentos, as crianças também se apropriam do repertório da cultura corporal na qual estão inseridas. Nesse sentido, as instituições de educação infantil devem fornecer um ambiente físico e social onde as crianças se sintam protegidas e acolhidas, e ao mesmo tempo seguras para se arriscar e vencer desafios. Quanto mais rico e desafiador for esse ambiente, mais ele lhes possibilitará a ampliação de conhecimentos acerca de si mesmas, dos outros e do meio em que vivem.

Outro documento oficial importante que norteia as propostas curriculares e projetos pedagógicos são as Diretrizes Curriculares Nacionais para a Educação Infantil (BRASIL, 1998), as quais estabelecem: “[...] (c) princípios estéticos da sensibilidade, da criatividade, da ludicidade e da diversidade de manifestações artísticas e culturais" (art. $3^{\circ}$, IV), dentre outros. Já o documento Política Nacional de Educação Infantil (BRASIL, 2006), do Ministério da Educação (MEC), ratifica as Diretrizes e considera que "o processo pedagógico deve considerar as crianças em sua totalidade, observando suas especificidades, as diferenças entre elas e sua forma privilegiada de conhecer o mundo por meio do brincar" (p. 17).

Fica evidente, tanto em leis e documentos oficiais, o direito das crianças ao cuidado, à educação e ao brincar. Mas, para além das exigências e determinações legais, buscamos ampliar nossas discussões, entendendo que a ludicidade no espaço escolar não se restringe à presença de jogos e brincadeiras infantis.

Concordamos com a definição de Luckesi (2000), quando apresenta a ludicidade como um fazer humano mais amplo, que se relaciona não apenas à presença de brincadeiras ou jogos, mas também a sentimentos, atitudes dos sujeitos envolvidos na ação, 
que se referem a um prazer de celebração em função do envolvimento genuíno com uma atividade, uma sensação de plenitude que acompanha processos formativos significativos e verdadeiros.

O lúdico permite tanto às crianças quanto aos adultos desenvolverem confiança em si mesmos e em suas capacidades. Em situações sociais, ajuda-os a serem empáticos com os outros e a ampliarem os processos de interação social, oportunizando-lhes a exploração dos próprios potenciais e limitações, além de experimentarem liberdade e desenvolvimento da independência. Para Ortiz (2005, p. 10),

O ensino deve favorecer uma participação mais ativa por parte da criança no processo educativo. Deve-se estimular as atividades lúdicas como meio pedagógico que, junto com outras atividades, como as artísticas e musicais, ajudem a enriquecer a personalidade criadora, necessária para enfrentar os desafios na vida. Para qualquer aprendizagem, tão importante como adquirir, é sentir os conhecimentos [...]. Divertir-se enquanto aprende e envolver-se com a aprendizagem, fazem com que a criança cresça, mude e participe ativamente do processo educativo.

O lúdico tal como esboçado neste estudo sugere mudanças no processo educativo, principalmente na educação infantil, a fim de romper com o entendimento de alguns de que a brincadeira e o jogo infantil são atividades de "passatempo" sem nenhuma importância pedagógica, ao contrário, é necessário valorizar, estimular e propiciar o lúdico no âmbito da sala de aula. "Daí, considerarmos a significação trazida pelas atividades lúdicas no espaço da educação infantil, pois concretiza a história do grupo, com o brilho das imagens, objetos, cores e sons, podendo catalisar diferentes formas de ver o mundo" (PEREIRA, 2005, p. 4).

A incorporação da dimensão lúdica no cotidiano da educação infantil transforma a organização do espaço-tempo escolar e, principalmente, as relações estabelecidas entre criança-criança e criança-professora. Para isso, torna-se importante conhecermos melhor as crianças, as possibilidades do lúdico na educação infantil e o que está em jogo na vida cotidiana de nossas crianças e professoras. Como brincam? Por quais jogos se interessam? Quais são os temas de suas brincadeiras? Quais objetos utilizam? Como os utilizam? E, por que o fazem?

Concordamos com Kishimoto (2003, p. 28) ao afirmar que:

Fatores como a definição do lugar que a criança ocupa num determinado contexto social, a identificação da forma de educação a que está submetida e o tipo de relações sociais que ela mantém com personagens do seu meio permitem a compreensão da imagem de criança e do comportamento do brincar. Ao analisar o cotidiano infantil, é preciso constatar as marcas da heterogeneidade e a presença de valores hierárquicos que dão sentido às imagens culturais da época. Tais imagens construídas por personagens que fazem parte desse contexto não decorrem de concepções psicológicas e científicas, mas muito mais de informações, valores e preconceitos oriundos da vida cotidiana.

As crianças, nas relações que estabelecem com o seu meio, inclusive na escola, vão (re)construindo o seu conhecimento, suas habilidades, enfim, seus jeitos de ser como pessoa; as atividades lúdicas, de acordo com sua multidimensionalidade, permitem que as crianças criem situações imaginárias, manipulem dados da realidade, compreendendo-a, 
(re)elaborando-a e transformando-a. Através do brinquedo e nas suas relações sociais, a criança aprende de um jeito particular (aprende do jeito que lhe é próprio); ela brinca, cria, imagina, inventa, aprende e ensina a partir daquilo que vivencia na realidade. Essa hipótese sustenta-se nos princípios teóricos apresentados por Vigotskii (1987), que, ao discutir a atividade imaginativa e criadora da criança em seu ensaio La imaginación y el arte en la infância, destaca que

Os processos criadores se apresentam desde a mais tenra infância [...]. Desde os primeiros anos de sua infância, encontramos processos criadores que se refletem, sobretudo, em seus jogos. A criança que cavalga sobre um pau e se imagina que monta um cavalo. A menina que joga com sua boneca e se crê mãe, os meninos que jogam aos ladrões, aos soldados, aos marinheiros, todos eles mostram em seus jogos exemplos da mais autêntica criação [...]. O afã que sentem de fantasiar as coisas é reflexo de sua atividade imaginativa, como nos jogos (p. 11-12).

Portanto, ensinar e aprender numa perspectiva lúdica implica numa reinvenção do ambiente pedagógico, deixando-o mais favorável às crianças e professoras, mais cooperativo e interativo. O desenvolvimento de tal perspectiva requer uma escuta e olhar (ver, sentir, tocar) sensíveis ao cotidiano da escola, constituído de movimentos que se repetem, (re)criam, inovam e renovam, sendo que o conhecimento da história e o respeito aos saberes, à diversidade diferenças dos sujeitos é requisito importante para viabilização dessas proposições.

\section{Considerações Finais}

A viabilização de uma cultura lúdica e estética requer um esforço e labor coletivos, movidos por uma epistemologia social, crítica, reflexiva e sensível aos choques e resistências, pois trata-se de tocar em estruturas sociais, culturais e disciplinares historicamente constituídas. Mas é preciso apostar também nas possibilidades de transformação de nossos rígidos espaços-tempos de vida cotidiana, na tentativa de se (re) construir um diálogo multicultural em meio às diversas culturas silenciadas. Assim,

Chegamos, portanto, através de um caminho tortuoso, à seguinte conclusão: a verdadeira civilização não pode existir sem um certo elemento lúdico, porque a civilização implica a limitação e o domínio de si próprio, a capacidade de não tomar suas próprias tendências pelo fim último da humanidade, compreendendo que está encerrado dentro de certos limites livremente aceites (HUIZINGA, 2000, p. 234).

Para viabilizar uma cultura lúdica e uma educação estética, torna-se necessário considerar que as práticas sociais e culturais relacionadas ao lúdico constituem-se importantes eixos para formação de sujeitos, e são espaços/tempos no interior dos quais poderão aprender uns com os outros e também se compreender melhor. 


\section{Referências}

ARCE, Alessandra. Friedrich Froebel: o pedagogo dos jardins de infância. Petrópolis/RJ: Vozes, 2002.

ARIÈS, Philippe. História social da criança e da família. 2 ed. Rio de Janeiro: LTC, 1981.

BENJAMIN, Walter. Reflexões sobre a criança, o brinquedo e a educação. São Paulo: Editora 34, 2002.

. Obras escolhidas. Vol I. Magia e técnica, arte e política. 7 ed. São Paulo: Brasiliense, 1994.

BRASIL. Lei 9.394/96, de 20/12/1996. Estabelece as Diretrizes e Bases da Educação Nacional. Brasília: MEC, 1996.

Ministério da Educação. Subsídios para Credenciamento e Funcionamento de Instituições de Educação Infantil. Brasília: MEC/SEF, 1998a.

Referencial Curricular Nacional para a Educação Infantil. vol. 1, 2 e 3. Brasília: MEC/SEF, 1998b.

Diretrizes Curriculares Nacionais para a Educação Infantil. Resolução CNE/CEB n 1 , de 07/04/1999. dos Deputados, 1998.

Constituição da República Federativa do Brasil (1988). 10 ed. Brasília: Câmara Lei 8.069/90, de 13/07/1990. Estatuto da Criança e do Adolescente. Rio de Janeiro: Expressão e Cultura, 2001.

BROUGÈRE, Gilles. Jogo e educação. Porto Alegre: Artes Médicas, 1998.

Brinquedo e cultura. 3 ed. São Paulo: Cortez, 2000.

. A criança e a cultura lúdica. In: KISHIMOTO, Tizuko (Org.). O brincar e suas teorias. São Paulo: Pioneira Thomson Learning, 2002.

Brinquedos e companhia. São Paulo: Cortez, 2004.

BUJES. Maria Isabel. Criança e brinquedo: feitos um para o outro? In: COSTA, Marisa Vorraber (Org.). Estudos culturais em educação: mídia, arquitetura, brinquedo, biologia, literatura e cinema. Porto Alegre: Editora da UFRGS, 2000.

CAILLOIS, Roger. Los juegos y los hombres: la máscara y el vértigo. México: Fondo de Cultura Económica, 1986.

FARIA, Ana Lúcia Goulart de. Educação pré-escolar e cultura. 2 ed. São Paulo: Cortez, 2002. 
FRIEDMANN, Adriana. Brincar: crescer e aprender - o resgate do jogo infantil. São Paulo: Moderna, 1996.

FROEBEL, Friedrich A. A educação do homem. Tradução: Maria Helena Câmara Bastos. Passo Fundo: UPF, 2001.

GEERTZ, Clifford. A interpretação das culturas. Tradução: Fanny Wrobel. Rio de Janeiro: Zahar Editores, 1978.

HUIZINGA, Johan. Homo ludens. 4 ed. São Paulo: Perspectiva, 2000.

KISHIMOTO, Tizuko Morchida. Escolarização e brincadeira na educação infantil. In: SOUSA, Cynthia Pereira de. História da Educação: processos, práticas e saberes. São Paulo: Escrituras, 1998.

Jogo, brinquedo, brincadeira e a educação. São Paulo: Cortez, 2000.

O jogo e a educação infantil. São Paulo: Pioneira Thomsom Learning, 2003.

KRAMER, Sônia. A política do pré-escolar no Brasil: a arte do disfarce. 4 ed. São Paulo: Cortez, 1992.

KUHLMANN JR, Moysés. Histórias da educação infantil brasileira. Revista Brasileira de Educação, n. 14, p. 5-18, maio/ago. 2000.

O jardim-de-infância e a educação das crianças pobres - final do século XIX, início do século XX. In: MONARCHA, Carlos (Org). Educação da infância brasileira 1875-1983. São Paulo: Autores Associados, 2001.

LUCKESI, Cipriano Carlos. Educação, ludicidade e prevenção das neuroses futuras: uma proposta pedagógica a partir da Biossíntese. In: LUCKESI, Cipriano Carlos (org). Ludopedagogia - Ensaios 1: educação e ludicidade. Salvador: Faced/UFBA, 2000.

UNICEF. Convenção sobre os Direitos da Criança. Disponível em: http://www.unicef.org.br. Acesso em: 15 maio 2007.

. Declaração dos Direitos da Criança. Disponível em: http://www.unicef.org.br. Acesso em: 15 maio 2007.

ORTIZ, Jesús Paredes. Aproximação teórica à realidade do jogo. In: MURCIA, Juan Antonio Moreno (Org.). Aprendizagem através do jogo. Porto Alegre: Artmed, 2005.

PEREIRA, Reginaldo Santos. Laboratório de Ludopedagogia da UESB: espaço e tempo de aprendizagens e formação docente. In: XVII Encontro de Pesquisadores em Educação do Norte e Nordeste - EPENN, Anais do EPENN, Belém-PA, jun. 2005.

ROCHA, Maria Silvia Pinto de Moura Librandi da. Não brinco mais: a (des)construção do brincar no cotidiano educacional. 2 ed. Ijuí-Rio Grande do Sul: Unijuí, 2005.

RODRIGUES, Gutemberg Alexandrino. Os filhos do mundo: a face oculta da menoridade 91964 - 1979). São Paulo: IBCCRIM, 2001. 


\title{
SCHILLER, Friedrich. A educação estética do homem. Tradução: Roberto Schwarz e
} Márcio Suzuki. São Paulo: Iluminuras, 1990.

\section{VIGOTSKI, L. S. La imaginación y el arte en la infancia. México: Ediciones y}

Distribuiciones Hispânicas, 1987.

WAJSKOP, Gisela. Brincar na pré-escola. 2. ed. São Paulo: Cortez, 1997.

\begin{abstract}
${ }^{1}$ Os dons são brinquedos ou materiais educativos; eles seriam uma espécie de "presentes" dados às crianças, ferramentas para ajudá-las a descobrir os seus próprios dons, isto é, descobrir o presente que Deus teria dado a cada uma delas. Os dons são materiais como bola, cubo, varetas, anéis, triângulos coloridos, círculos e objetos como materiais de modelagem, fitas e sementes de feijão, flores etc. (ARCE, 2002).

2 "O nome roda provém do dispositivo onde se colocavam os bebês que se queriam abandonar. Sua forma cilíndrica, dividida ao meio por uma divisória, era fixada no muro ou janela da instituição. No tabuleiro inferior e em sua abertura externa, o expositor depositava a criança que enjeitava. A seguir, ele girava a roda e a criança já estava do outro lado do muro. Puxava-se uma cordinha com uma sineta para avisar que um bebê acabava de ser abandonado e o expositor furtivamente retirava-se do local, sem ser identificado"
\end{abstract}

(MARCILIO, 2001, p. 57).

${ }^{3}$ Com a Constituição Federal de 1988 e o ECA, o Brasil adere formalmente à concepção da criança como sujeito de direitos, detentora de potencialidades a serem desenvolvidas, em sintonia com as normativas internacionais: Declaração Universal dos Direitos da Criança (UNICEF, 1959) e Convenção sobre os Direitos da Criança (UNICEF, 1989).

${ }^{4}$ Art. 227. É dever da família, da sociedade e do Estado assegurar à criança e ao adolescente, com absoluta prioridade, o direito à vida, à saúde, à alimentação, à educação, ao lazer, à profissionalização, à cultura, à dignidade, ao respeito, à liberdade e à convivência familiar e comunitária, além de colocá-los a salvo de toda forma de negligência, discriminação, exploração, violência, crueldade e opressão (BRASIL, Constituição Federal de 1988).

Recebido: julho-15 Aprovado: outubro-15 